\title{
Engineering a Catalytic Metal Binding Site into a Calcium-Independent Phosphatidylinositol-Specific Phospholipase C Leads to Enhanced Stereoselectivity ${ }^{\dagger}$
}

\author{
Alexander V. Kravchuk, ${ }^{\ddagger}, \|$ Li Zhao, ${ }^{\ddagger}, \S$ Karol S. Bruzik, ${ }^{\perp}$ and Ming-Daw Tsai*,» \\ Department of Chemistry and Biochemistry, the Ohio State University, Columbus, Ohio 43210, and \\ Department of Medical Chemistry and Pharmacognosy, University of Illinois at Chicago, Chicago, Illinois 60612
}

Received November 19, 2002; Revised Manuscript Received January 8, 2003

\begin{abstract}
Eukaryotic phosphatidylinositol-specific phospholipase Cs (PI-PLCs) utilize calcium as a cofactor during catalysis, whereas prokaryotic PI-PLCs use a spatially conserved guanidinium group from Arg69. In this study, we aimed to construct a metal-dependent mutant of a bacterial PI-PLC and characterize the catalytic role of the metal ion, seeking an enhanced understanding of the functional differences between these two positively charged moieties. The following results indicate that a bona fide catalytic metal binding site was created by the single arginine-to-aspartate mutation at position 69: (1) The R69D mutant was activated by $\mathrm{Ca}^{2+}$, and the activation was specific for R69D, not for other mutants at this position. (2) Titration of R69D with $\mathrm{Ca}^{2+}$, monitored by ${ }^{15} \mathrm{~N}-{ }^{1} \mathrm{H}$ HSQC (heteronuclear single quantum coherence) NMR, showed that addition of $\mathrm{Ca}^{2+}$ to R69D restores the environment of the catalytic site analogous to that attained by the WT enzyme. (3) Upon $\mathrm{Ca}^{2+}$ activation, the thio effect of the $S_{\mathrm{P}^{-}}$ isomer of the phosphorothioate analogue $\left(k_{O} / k_{S \mathrm{p}}=4.4 \times 10^{5}\right)$ approached a value similar to that of the WT enzyme, suggesting a structural and functional similarity between the two positively charged moieties (Arg69 and Asp69- $\left.\mathrm{Ca}^{2+}\right)$. The $R_{\mathrm{P}}$-thio effect $\left(k_{O} / k_{R \mathrm{p}}=9.4\right)$ is smaller than that of the WT enzyme by a factor of 5. Consequently, R69D-Ca ${ }^{2+}$ displays higher stereoselectivity $\left(k_{R \mathrm{p}} / k_{S \mathrm{p}}=47000\right)$ than WT $\left(k_{R \mathrm{p}} /\right.$ $k_{S \mathrm{p}}=7600$ ). (4) Results from additional mutagenesis analyses suggest that the $\mathrm{Ca}^{2+}$ binding site is comprised of side chains from Asp33, Asp67, Asp69, and Glu117. Our studies provide new insight into the mechanism of metal-dependent and metal-independent PI-PLCs.
\end{abstract}

Engineering of metal binding sites in proteins (reviewed in refs $1-3$ ) has been used to address a variety of problems such as protein-protein interactions and topology of transmembrane domains $(4,5)$, regulation of enzyme activity and specificity $(6,7)$, and modification of enzyme redox chemistry (8). Surprisingly, the interchange between positively charged amino acid side chains and metal ions was successfully achieved only in the metal to amino acid direction (9). To the best of our knowledge, there are no examples in the literature describing a catalytic metal site that would replace, completely or partially, the function of a lysine or an arginine side chain.

Phosphatidylinositol-specific phospholipase Cs (PIPLCs ${ }^{1}$; EC 3.1.4.10) play a key role in numerous signal transduction pathways in eukaryotic organisms $(10-13)$. While the biological role of bacterial PI-PLCs is not clear, it has been shown that these enzymes may contribute to virulence of the respective microorganisms $(14,15)$. Since both eukaryotic and bacterial enzymes appear to catalyze the same chemical reactions $(12,16-19)$, bacterial PI-PLCs

$\dagger$ This work was supported by a grant from the National Institutes of Health (GM57568).

* To whom correspondence should be addressed. Telephone: (614) 292-3080. Fax: (614) 292-1532. E-mail: tsai.7@osu.edu.

$\doteqdot$ Ohio State University.

$\S$ The first two authors contributed equally to this work.

"Present address: Department of Biochemistry, B400 Beckman Center, Stanford University, Stanford, CA 94305.

${ }^{\perp}$ University of Illinois at Chicago. have been a favorite model system in mechanistic and structural studies because of their low molecular weight and absence of regulatory domains (20-25). However, there are significant differences between these two types of enzymes: bacterial enzymes accept only nonphosphorylated phosphatidylinositol (PI) substrates and produce mainly cyclic inositol phosphate (IcP), which is subsequently hydrolyzed at a rate that is 1000-fold slower; in contrast, mammalian enzymes prefer phosphorylated PI substrates and produce IcP and inositol phosphates (IP) simultaneously.

Both mammalian and bacterial PI-PLCs have been proposed to utilize the general acid and general base mechanisms to catalyze the hydrolysis of PI (Figure 1), yet their catalytic sites are quite different, as shown in Figure 2A (mammalian PI-PLC- $\delta 1$ ) and Figure 2B (Bacillus PIPLC). However, there is a striking similarity of the spatial arrangement between the calcium ion in mammalian PIPLC- $\delta 1$ (mPI-PLC) and the arginine side chain in Bacillus PI-PLC (bPI-PLC) $(18,19,26)$. Both structural information

\footnotetext{
${ }^{1}$ Abbreviations: DAG, sn-1,2-diacylglycerol; DHPC, diaheptanoyl$s n$-glycero-3-phosphocholine; DPPsI, 1,2-dipalmitoyl-sn-glycero-3-(1thiophospho-1D-myo-inositol); EDTA, ethylenediaminetetraacetic acid; HEPES, $N$-(2-hydroxyethyl) piperazine- $N^{\prime}$-(2-ethanesulfonic acid); HSQC, heteronuclear single quantum coherence; $\left[{ }^{3} \mathrm{H}\right]-\mathrm{PI}, \mathrm{L}-\alpha-[$ myoinositol-2- $\left.{ }^{3} \mathrm{H}(\mathrm{N})\right]$-phosphatidylinositol; IP, inositol 1-phosphate; IcP, inositol 1,2-cyclic phosphate; NMR, nuclear magnetic resonance; NOESY, nuclear Overhauser enhancement spectroscopy; PI, phosphatidylinositol; PI-PLC, phosphatidylinositol-specific phospholipase $\mathrm{C}$; Tris, tris (hydroxyethyl) aminomethane; WT, wild type.
} 


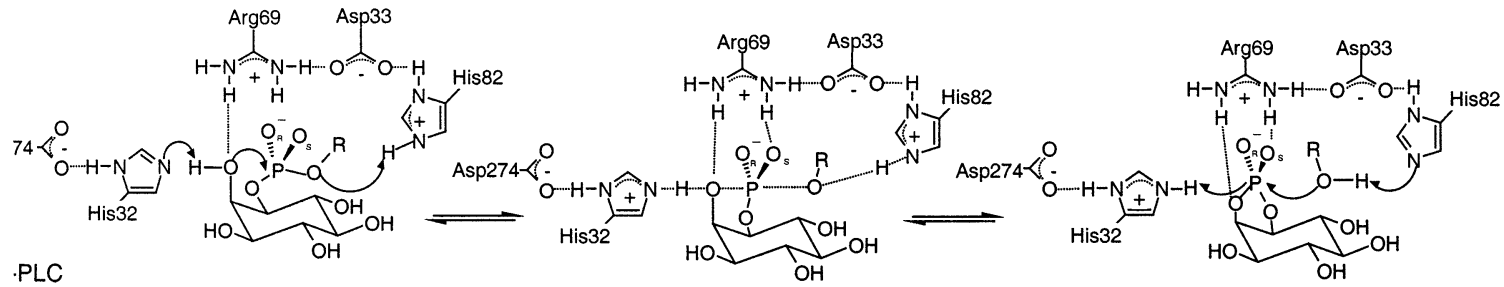

Phosphotransferase $(R=D A G)$

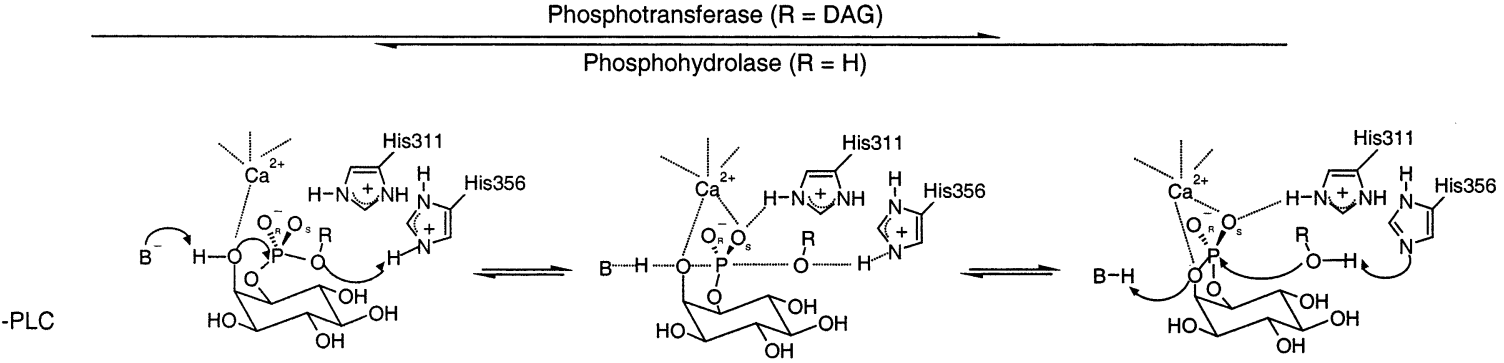

FIGURE 1: Proposed general acid/general base catalytic mechanisms for bPI-PLC (Bacillus PI-PLC) and mPI-PLC (mammalian PIPLC- $\delta 1)$. The identity of the general base $\left(\mathrm{B}^{-}\right)$in $\mathrm{mPI}-\mathrm{PLC}$ is not yet clear. DAG, sn-1,2-diacylglycerol. At physiological condition, bPI-PLC catalyzes only the first step of reaction (phosphotransferase step) and releases cyclic inositol phosphate as a final product, whereas $\mathrm{mPI}-\mathrm{PLC}$ produces IcP and inositol phosphate (IP) simultaneously, with IP as the major product.

and the results from stereochemical and mutagenesis studies have indicated that these two similarly positioned positively charged moieties play similar catalytic roles: both stabilize the transition state of the phosphoryl transfer reaction via interaction with pro-S oxygen of the phosphodiester moiety and facilitate deprotonation of the 2-OH of the inositol ring $(16,18,27-29)$. However, it is not clear whether, and how, the use of $\mathrm{Ca}^{2+}$ versus Arg could be responsible for the differences in the substrate specificity and the product profile (ratio of the cyclic to acyclic product) between mammalian and bacterial enzymes. To address these questions, efforts from other laboratories have been devoted to engineering the $\mathrm{Ca}^{2+}$-independent PI-PLC into a $\mathrm{Ca}^{2+}$-dependent enzyme, and vice versa, but so far without success. Specifically, the double mutant bPI-PLC (R69D/K115E) displayed no detectable catalytic activity in either the absence or presence of $\mathrm{Ca}^{2+}$, although it was shown to be folded correctly (19). The authors suggested that the $\mathrm{Ca}^{2+}$-binding site in mPIPLC probably has very stringent steric and electronic requirements (19). Conversely, an attempt to eliminate the $\mathrm{Ca}^{2+}$-dependence of mPI-PLC also failed as the calcium affinity was not mitigated upon mutating the negatively charged calcium binding residues (E390K, E343R, or E390K/ E343R) (30). It was suggested that the role of calcium is not restricted to providing a positive charge but is also involved in sterically accelerating catalysis via additional interactions with the transition state (30).

This paper describes successful conversion of bPI-PLC into a metal-dependent enzyme by R69D mutation. The kinetic data demonstrate that the presence of $\mathrm{Ca}^{2+}$ activates the catalytic activity of this mutant substantially, while the structural data obtained by NMR spectroscopy indicate that presence of $\mathrm{Ca}^{2+}$ is essential for restoring the microenvironment of the catalytic site of the mutant to that attained by the wild type (WT) enzyme. We also used $R_{\mathrm{P}^{-}}$and $S_{\mathrm{P}^{-}}$ isomers of the phosphorothioate analogues of phosphatidylinositol to probe the role of $\mathrm{Ca}^{2+}$ in catalysis. The results of the stereochemical study indicate that in the presence of $\mathrm{Ca}^{2+}$ R69D is highly specific for the $R_{\mathrm{P}}$-isomer of DPPsI, and its
$R_{\mathrm{P}} / S_{\mathrm{P}}$ stereoselectivity is 5 -fold higher than the $R_{\mathrm{P}} / S_{\mathrm{P}}$ ratio of WT bPI-PLC. In addition, this constructed $\mathrm{Ca}^{2+}$ binding site was further characterized by site-directed mutagenesis studies and kinetic analyses.

\section{MATERIALS AND METHODS}

Materials. DPPsI was synthesized as reported previously (16). PI from bovine liver and 1,2-diheptanoyl-sn-glycero3-phosphocholine (DHPC) were purchased from Avanti Polar Lipids. L- $\alpha-\left[m y o-i n o s i t o l-2-{ }^{3} \mathrm{H}(\mathrm{N})\right]$ Phosphatidylinositol $\left(\left[{ }^{3} \mathrm{H}\right]-\right.$ PI) was purchased from Dupont NEN. ${ }^{15} \mathrm{NH}_{4} \mathrm{Cl}\left(\right.$ at $\left.99 \%{ }^{15} \mathrm{~N}\right)$ was from Isotech Inc. Oligonucleotides were purchased from Integrated DNA Technologies, Inc. The Escherichia coli strains XL1 Blue and BL21 (DE3) LysE used for gene manipulation and protein overexpression were from Stratagene. All DNA-modifying enzymes were from New England Biolabs. Both $99.9 \%$ atom $\mathrm{D}_{2} \mathrm{O}$ and $100 \% \mathrm{D}_{2} \mathrm{O}$ were purchased from Cambridge Isotope Laboratories.

Construction and Purification of Metal Dependent Variants. Mutations were introduced by the double-stranded, sitedirected mutagenesis method (Stratagene). The mutagenic primers used are listed $5^{\prime}$ to $3^{\prime}$ with base substitutions underlined and codons of interest in italics. Only forward primer sequences are shown for each mutant oligonucleotide, and the mutation produced is in parentheses: 5'-CGC ATT TTT GAT ATC GATGGA CGT TTA ACA GAT G-3' (R69D); 5'-CGC ATT TTT GAT ATA GAG GGA CGT TTA ACA GAT G-3' (R69E); 5'-CGC ATT TTT GAT ATC $A A C$ GGA CGT TTA ACA GAT G-3' (R69N); 5'CGC ATT TTT GAT ATC GCA GGA CGA CGT TTA ACA G-3' (R69A); 5'-CGC ATT TTT GAT ATC GGA GGA CGA CGT TTA ACA G-3' (R69G); 5'-GGA GCT CGC ATT TTT AAT ATT GAT GGA CG-3' (D67N/R69D); 5'- GGA GCT CGC ATT TTT GAA ATT GAT GGA CG-3' (D67E/R69D); 5'- CCA ATT ATTे ATG TCT TTA AAA AAA $C A G$ TAT GAG GAT ATG-3' (E117Q); 5'-CAA TTC CAG GAA CAC ACG AAA GTG GGA CG-3' (D33E). Mutant D33N/R69D was constructed by using the R69D 


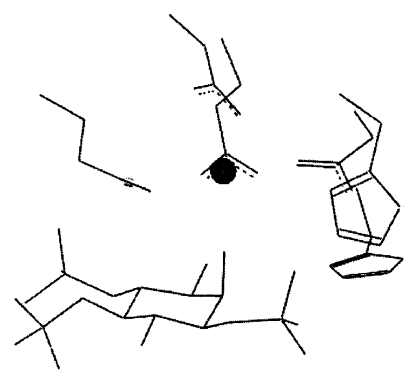

A
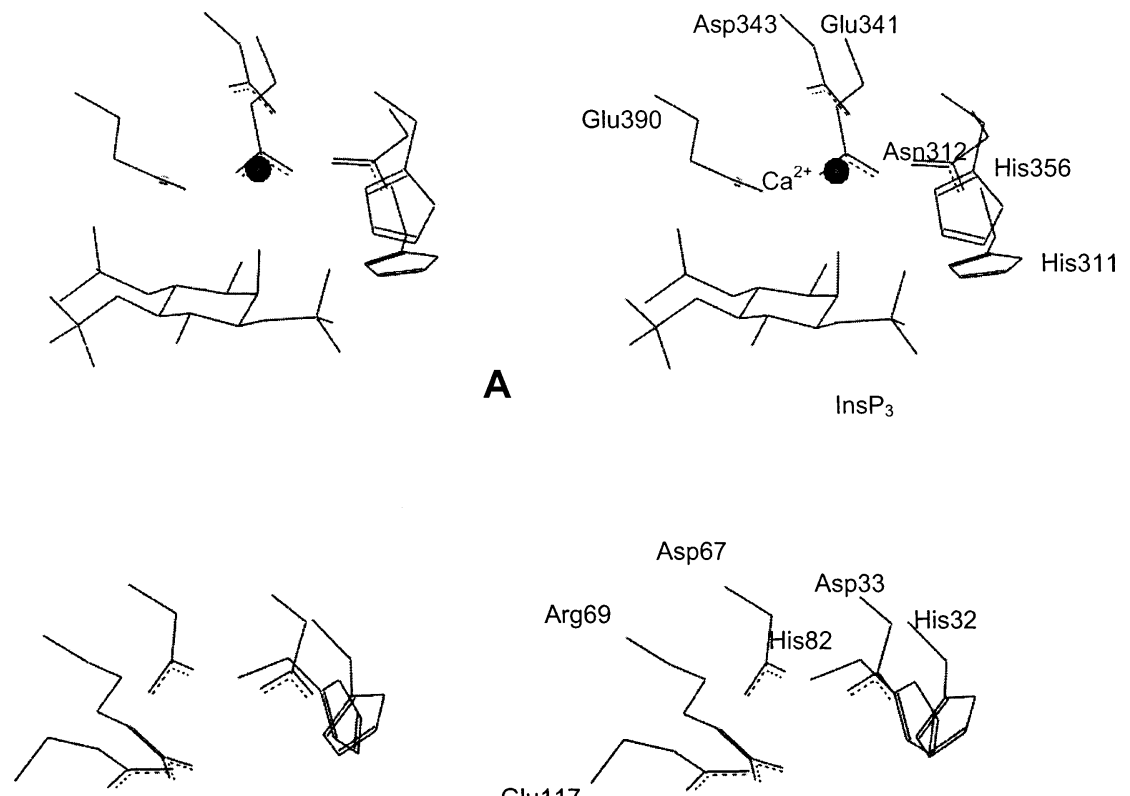

Glu117
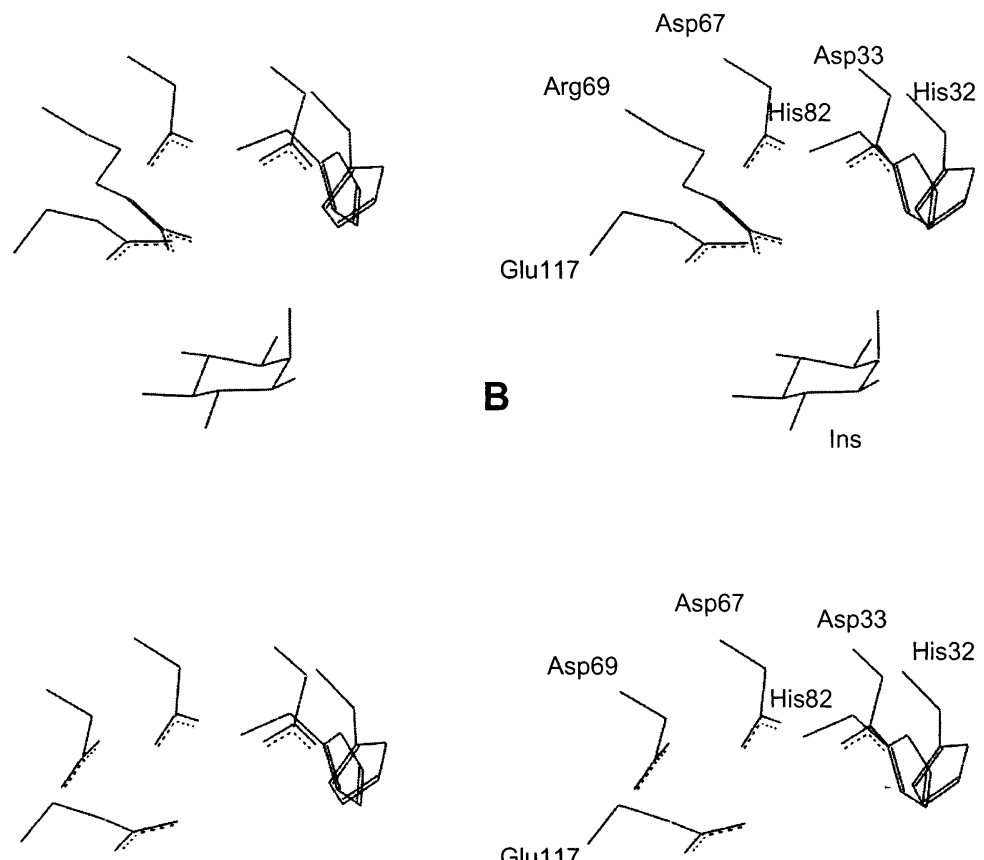

B

Ins
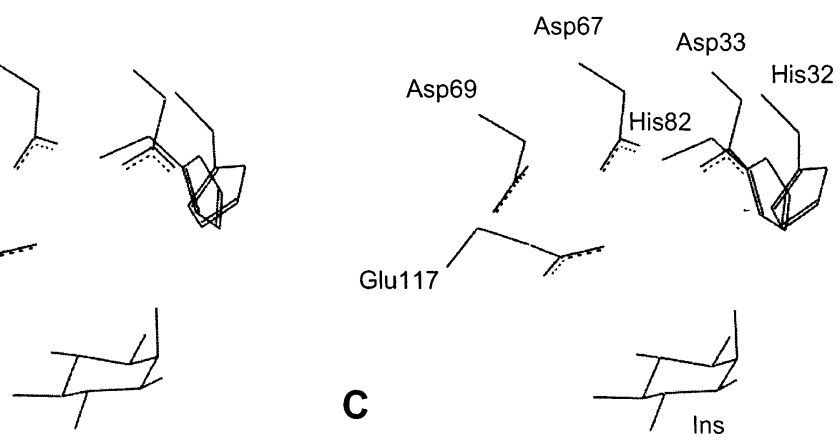

FIGURE 2: Side-by-side comparison of the active sites (stereoview) of the mammalian PI-PLC- $\delta 1$ (A), WT Bacillus PI-PLC (B), and the R69D mutant Bacillus PI-PLC (C). A, B, and C are adapted from PDB files 1DJX, 1PTG, and 1PTG, respectively, and were prepared with the WebLab ViewerPro. The program SwissModel was used to construct the model structure for R69D shown in panel C. Panel A shows two conservative histidine residues and other side chains that form the calcium coordination sphere and the bound inositol triphosphate within the active site. Panel B shows Arg69, His32, His82, side chains of residues (Asp33, Asp67, and Glu117) that form hydrogenbonding interactions with Arg69, and the bound inositol within the active site of the WT bacterial PI-PLC. Panel C represents the active site of the mutant R69D enzyme, constructed by SwissModel with energy minimization. Ins, inositol. InsP ${ }_{3}$, D-myo-inositol 1,4,5-triphosphate.

primer on the existing plasmid carrying the mutant D33N gene. All mutations were verified by sequencing. Mutant R69C was constructed previously (28). All mutant proteins were purified as described previously $(22,24)$, except that all but the final dialysis buffer included $1 \mathrm{mM}$ EDTA to prevent metal contamination.

Activity Assay of PI-PLC with $\left[{ }^{3} H\right]-P I$ Substrate. The specific activities of mutants were measured according to the procedure reported earlier (28) with minor modifications. $\left[{ }^{3} \mathrm{H}\right]$-PI was mixed with unlabeled PI from bovine liver to obtain an overall PI concentration of $5 \mathrm{mM}$ and a specific activity of ca. $1.25 \times 10^{6} \mathrm{cpm} / \mathrm{mol}$. In the divalent metal ion activation study, the reaction mixture contained $2 \mathrm{mM}$ PI, $8 \mathrm{mM}$ DHPC, $0-2 \mathrm{mM} \mathrm{MeCl} 2,1 \mathrm{mM}$ EDTA, and 40 mM HEPES, pH $7.5(\mathrm{NaOH})$. In the monovalent metal ion activation study, the reaction mixture contained $2 \mathrm{mM}$ PI, 8
$\mathrm{mM}$ DHPC, 0-50 mM MeCl, and $40 \mathrm{mM}$ HEPES, $\mathrm{pH} 7.5$, where the $\mathrm{pH}$ of the buffer was adjusted by Tris instead of $\mathrm{NaOH}$ to avoid introduction of sodium ions. In the monovalent metal ion inhibition study, the mixture included $2 \mathrm{mM}$ PI, $8 \mathrm{mM}$ DHPC, $1 \mathrm{mM} \mathrm{CaCl}_{2}, 0-50 \mathrm{mM} \mathrm{MeCl}$, and 40 $\mathrm{mM}$ HEPES, pH 7.5 (Tris base). An aliquot of $20 \mu \mathrm{L}$ of PI-PLC solution was added to the reaction mixture and incubated at $37{ }^{\circ} \mathrm{C}$ for $10 \mathrm{~min}$. The concentrations of enzymes were adjusted so that the substrate conversion does not exceed $10-30 \%$. The reaction was stopped by the addition of $0.5 \mathrm{~mL} \mathrm{CHCl} / \mathrm{CH}_{3} \mathrm{OH} / \mathrm{HCl}$ (66:33:1). Phases were separated by a brief centrifugation, and radioactivity of $50 \mu \mathrm{L}$ of the aqueous phase was measured by scintillation counting (Beckman). Enzymatic activity was expressed in $\mu \mathrm{mol} \times \min ^{-1} \times(\mathrm{mg} \text { of protein })^{-1}$ or $\mathrm{U} / \mathrm{mg}$. 


\begin{tabular}{|c|c|c|c|}
\hline enzyme & 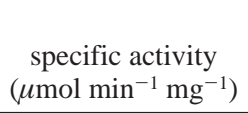 & $\begin{array}{c}\text { specific activity } \\
0.1 \mathrm{mM}\left[\mathrm{Ca}^{2+}\right]_{\text {free }} \\
\left(\mu \mathrm{mol} \mathrm{min}{ }^{-1} \mathrm{mg}^{-1}\right)\end{array}$ & 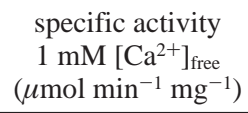 \\
\hline WT & $3560 \pm 80$ & $3450 \pm 98$ & $4240 \pm 13$ \\
\hline R69D & $0.293 \pm 0.009$ & $4.18 \pm 0.20$ & $8.67 \pm 0.01$ \\
\hline R69E & $0.044 \pm 0.001$ & $0.047 \pm 0.001$ & $0.047 \pm 0.000$ \\
\hline R69G & $0.023 \pm 0.0004$ & $0.021 \pm 0.001$ & $0.021 \pm 0.001$ \\
\hline R69A & $0.068 \pm 0.0031$ & $0.064 \pm 0.001$ & $0.065 \pm 0.001$ \\
\hline R69C & $0.168 \pm 0.0087$ & $0.149 \pm 0.003$ & $0.142 \pm 0.008$ \\
\hline R69N & $0.126 \pm 0.000$ & $0.116 \pm 0.002$ & $0.113 \pm 0.010$ \\
\hline D33N/R69D & $0.0024 \pm 0.0002$ & $0.0029 \pm 0.0001$ & $0.107 \pm 0.002$ \\
\hline D33E/R69D & $0.0052 \pm 0.0003$ & $0.0049 \pm 0.0002$ & $0.0054 \pm 0.0003$ \\
\hline D67N/R69D & $0.305 \pm 0.001$ & $0.289 \pm 0.005$ & $0.260 \pm 0.002$ \\
\hline D67E/R69D & $0.300 \pm 0.010$ & $0.278 \pm 0.010$ & $0.349 \pm 0.011$ \\
\hline R69D/E117Q & $0.414 \pm 0.004$ & $0.423 \pm 0.004$ & $0.367 \pm 0.005$ \\
\hline D33N/D67E/R69D & $0.0020 \pm 0.0001$ & $0.0019 \pm 0.0001$ & $0.0019 \pm 0.0001$ \\
\hline
\end{tabular}

${ }^{a}$ Measured at $37^{\circ} \mathrm{C}, 1 \mathrm{mM}$ EDTA, $2.0 \mathrm{mM}$ PI, and $8 \mathrm{mM}$ DHPC in $40 \mathrm{mM}$ HEPES buffer (pH 7.5).

$\mathrm{Ca}^{2+}$ Titration of R69D Monitored by NMR. Uniformly ${ }^{15} \mathrm{~N}$-labeled WT and R69D were expressed in M9 minimal media using ${ }^{15} \mathrm{NH}_{4} \mathrm{Cl}$ as a single nitrogen source and purified as described above. Two-dimensional ${ }^{15} \mathrm{~N}-{ }^{1} \mathrm{H}$ HSQC spectra of the uniformly ${ }^{15} \mathrm{~N}$-labeled protein at $\mathrm{Ca}^{2+}$ concentration ranging from 0 to $5 \mathrm{mM}$ were obtained on a Bruker DRX800 spectrometer at $37^{\circ} \mathrm{C}$. Each sample contained $0.4 \mathrm{mM}$ enzyme and $50 \mathrm{mM}$ HEPES buffer in $90 \% \mathrm{H}_{2} \mathrm{O} / 10 \% \mathrm{D}_{2} \mathrm{O}$, $\mathrm{pH} 7.5$.

${ }^{31} P$ NMR Assays with DPPsI. The assays were performed according to the procedure reported earlier (28). ${ }^{31} \mathrm{P}$ NMR spectra were recorded on a Bruker DRX-600 spectrometer at $242.88 \mathrm{MHz}$. The reactions were carried out at $25^{\circ} \mathrm{C}$ in $50 \mathrm{mM}$ HEPES buffer (pH 7.5). A mixture of $S_{\mathrm{P}^{-}}$and $R_{\mathrm{P}^{-}}$ isomers ( $\sim 6: 4$ ratio) of DPPsI at a total concentration of 10 $\mathrm{mM}$ and a 4-fold excess of DHPC were dispersed as micelles in a bath sonicator. For the reaction carried out in the absence of $\mathrm{Ca}^{2+}, 0.5 \mathrm{mM}$ EDTA was added to chelate any contaminating metal. For the reaction carried out in the presence of $\mathrm{Ca}^{2+}, 1.5 \mathrm{mM} \mathrm{CaCl}_{2}$ and $0.5 \mathrm{mM}$ EDTA were added. Reactions were initiated by adding an appropriate amount of the enzyme diluted in the reaction buffer, and a second aliquot of the enzyme was added after the reaction with the preferred $\left(R_{\mathrm{P}}\right)$ isomer had been completed. The rates of the reactions were calculated from the linear portions of the plot of the inositol 1,2-cyclic phosphate (IcP) concentration versus time.

\section{RESULTS AND DISCUSSION}

Construction of a Mutant Showing Activation by $\mathrm{Ca}^{2+}$. The design of the $\mathrm{Ca}^{2+}$ binding site was based on the similarity of the spatial arrangement between the calcium ion in mammalian PI-PLC- $\delta 1$ (mPI-PLC) and its counterpart arginine side chain in Bacillus PI-PLC (bPI-PLC). In addition, crystallographic structural data show that Arg69 of bPI-PLC is hydrogen bonded to three acidic residues (Asp33, Asp67, and Glu117) (Figure 2B), which are located in positions similar to those of Asn312, Glu341, Asp343, and Glu390 that form the coordination sphere of the calcium ion in mPI-PLC (Figure 2A) $(18,19,26)$. Therefore, eliminating the positive charge of Arg69 while maintaining the negative charges of Asp33, Asp67, and Glu117 as shown in Figure $2 \mathrm{C}$ provides a rough blueprint for the future metalbinding site proposed in our studies.
Our approach was first to construct a number of mutants (R69D, R69E, R69G, R69A, R69C, and R69N) and screen them for activation by $\mathrm{Ca}^{2+}$ under steady-state conditions, by monitoring the formation of IcP. Table 1 shows the activities of WT and various mutants in the conversion of PI to IcP, in the absence and presence of $\mathrm{Ca}^{2+}$ ions $(0.1$ and $1 \mathrm{mM})$. It is interesting that two mutants with carboxyl side chain substitutions at position 69, R69D and R69E, behave very differently. The R69E mutant is inactive $(0.044 \mathrm{U} / \mathrm{mg}$, as compared to $3560 \mathrm{U} / \mathrm{mg}$ for WT enzyme) and is not activated by any divalent metal ions tested, including $\mathrm{Ca}^{2+}$. R69D, on the other hand, is relatively active $(0.29 \mathrm{U} / \mathrm{mg})$ and can be further activated ca. 30-fold by $\mathrm{Ca}^{2+}$ addition. Mutants R69G, R69A, R69C, and R69N were also constructed, and their metal dependencies were examined. None of these constructs was activated by $\mathrm{Ca}^{2+}$. These initial results suggested that the presence of an aspartate residue at position 69 creates a catalytic metal binding site. Thus, further studies were carried out and focused on this mutant.

It is important to indicate that all of the assays described in this paper deal with the conversion of PI to IcP (the phosphotransfer reaction), not the hydrolysis of IcP, which occurs 1000 times slower. On the basis of ${ }^{31} \mathrm{P}$ NMR analysis, we found that like WT bPI-PLC, IcP is also the only detectable product for R69D- $\mathrm{Ca}^{2+}$ under our experimental conditions.

Metal Ion Specificity of the R69D Mutant. After showing the unique $\mathrm{Ca}^{2+}$ activation property of R69D, we examined the metal ion specificity of this mutant. The activation of R69D by alkaline earth metal ions was studied first. This mutant was activated to different extents by $\mathrm{Mg}^{2+}, \mathrm{Ca}^{2+}$, and $\mathrm{Sr}^{2+}$ as shown in Figure 3A. The enhanced activity of R69D by these metal ions obeyed saturation kinetics with respect to the metal ion concentration. Another alkaline earth metal ion, $\mathrm{Ba}^{2+}$, neither activated nor inhibited R69D bPI-PLC at concentrations up to $1 \mathrm{mM}$. The magnitude of R69D activation by different alkaline earth metal ions is summarized in Table 2. The maximal velocities of R69D complexes with $\mathrm{Mg}^{2+}, \mathrm{Ca}^{2+}$, and $\mathrm{Sr}^{2+}$ at saturating substrate concentration $(2 \mathrm{mM})$ were $10.2 \pm 0.2,12.0 \pm 0.3$, and 2.7 $\pm 0.3 \mathrm{U} / \mathrm{mg}$, which give a $35-, 41-$, and 9-fold activation, respectively. The results described above can be considered successful for a de novo metal binding site (31). For comparison, mPI-PLC was activated by $\mathrm{Ca}^{2+}$ at lower 

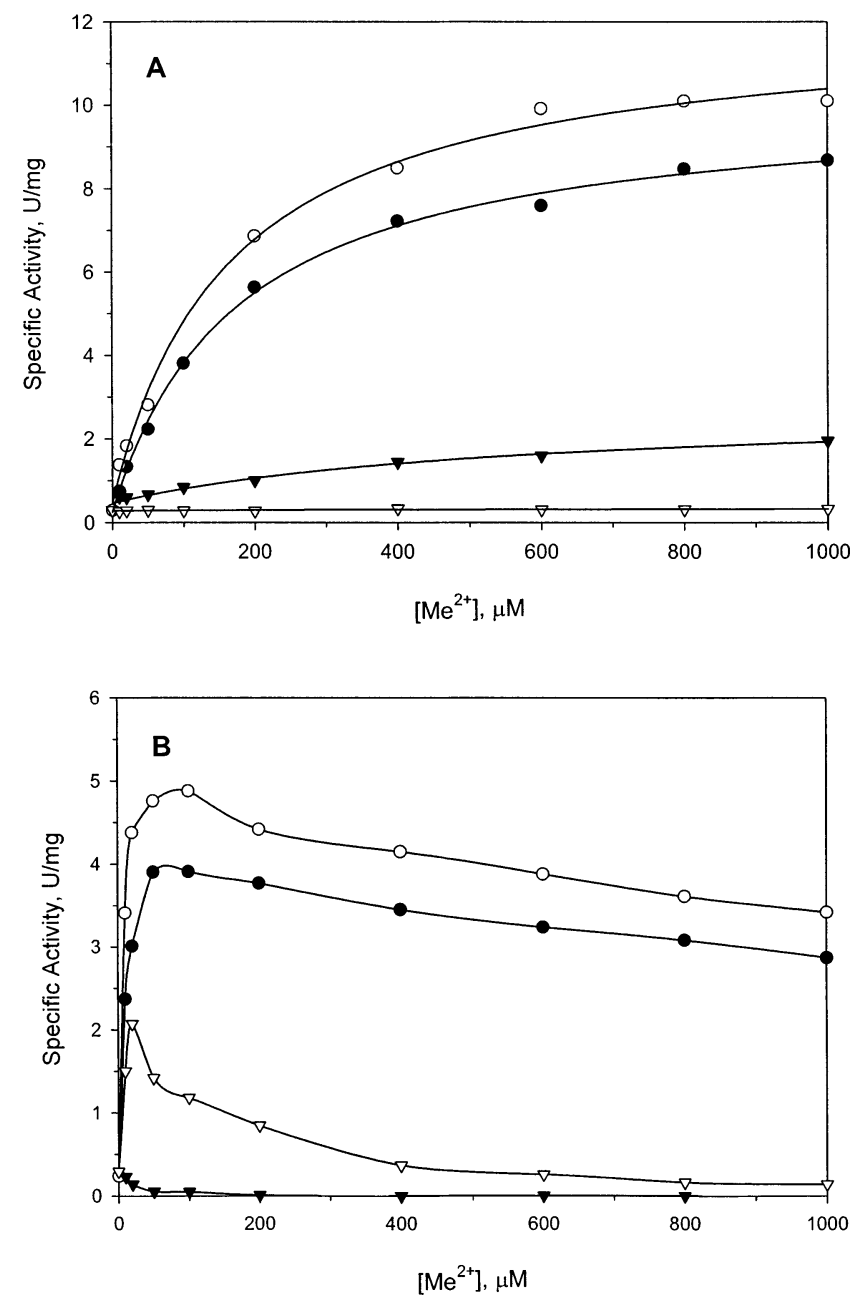

FIGURE 3: (A) Activation of R69D bPI-PLC by alkaline earth metal ions: calcium $(\bigcirc)$, magnesium $(\bullet)$, strontium $(\boldsymbol{\nabla})$, and barium $(\nabla)$. All reactions included $0.5-1.0 \mu \mathrm{g}$ R69D mutant in $40 \mathrm{mM}$ HEPEPS, $1 \mathrm{mM}$ EDTA, $2 \mathrm{mM}$ PI, $8 \mathrm{mM}$ DHPC, and 0-1 mM free metal ion, $\mathrm{pH}$ 7.0, for $10 \mathrm{~min}$ at $37^{\circ} \mathrm{C}$. Solid lines represent nonlinear fit of each data set to the Michaelis-Menten equation, $V=V_{\max }\left[\mathrm{M}^{2+}\right] /\left(K_{\mathrm{d}}^{\text {app }}+\left[\mathrm{M}^{2+}\right]\right)$, and the parameters are summarized in Table 2. The activity of R69D in the absence of metal ions $(0.29$ $\mathrm{U} / \mathrm{mg}$ ) was deducted prior to plotting. (B) Activation of R69D bPIPLC by transition metal ions: cobalt II (O), manganese II (O), cadmium II $(\nabla)$, and zinc II $(\nabla)$.

Table 2: Kinetic Parameters of R69D BPI-PLC with Alkaline Earth Metal Ions ${ }^{a}$

\begin{tabular}{ccc}
\hline metal ion & $\begin{array}{c}V_{\max } \\
\left(\mu \mathrm{mol} \mathrm{min} \mathrm{mg}^{-1}\right)\end{array}$ & $\begin{array}{c}K_{\mathrm{d}}^{\text {app }} \text { of } \mathrm{m}^{2+} \\
(\mathrm{mM})\end{array}$ \\
\hline $\mathrm{Mg}^{2+}$ & $0.29 \pm 0.01$ & $\mathrm{NA}^{b}$ \\
$\mathrm{Ca}^{2+}$ & $10.19 \pm 0.19$ & $0.18 \pm 0.01$ \\
$\mathrm{Sr}^{2+}$ & $11.93 \pm 0.33$ & $0.16 \pm 0.02$ \\
$\mathrm{Ba}^{2+}$ & $2.67 \pm 0.28$ & $0.49 \pm 0.13$ \\
\hline
\end{tabular}

${ }^{a}$ Measured at $37{ }^{\circ} \mathrm{C}, 1 \mathrm{mM}$ EDTA, $0-1 \mathrm{mM}$ free metal ion, 2.0 $\mathrm{mM}$ PI, and $8 \mathrm{mM}$ DHPC in $40 \mathrm{mM}$ HEPES buffer (pH 7.5). ${ }^{b}$ The $K_{\mathrm{i}}^{\text {app }}$ value for $\mathrm{Ba}^{2+}$ is extrapolated from Lineweaver-Burk plot using $\mathrm{Ba}^{2+}$ as an inhibitor of $\mathrm{Ca}^{2+} . K_{\mathrm{i}}^{\text {app }}$ is calculated by using the equation $K_{\mathrm{d}}^{\text {app' }}=K_{\mathrm{d}}^{\text {app }}\left(1+\left[\mathrm{I}_{0}\right] / K_{\mathrm{i}}^{\text {app }}\right)$, where $K_{\mathrm{d}}^{\text {app' }}$ is the $K_{\mathrm{d}}^{\text {app }}$ in the presence of 0.5 or $1.0 \mathrm{mM} \mathrm{Ba}^{2+}\left(\left[\mathrm{I}_{0}\right]\right)$.

concentrations (apparent dissociation constant for calcium: $\left.K_{\mathrm{d}}^{\mathrm{app}}=1.3 \mu \mathrm{M}\right)$ but not by $\mathrm{Mg}^{2+}$ at concentrations up to 5 $\mathrm{mM}(32,33)$. Further analyses of the data show that the extent of activation correlates roughly with $K_{\mathrm{d}}^{\text {app }}$ of the metal ion: $\mathrm{Ca}^{2+}$ and $\mathrm{Mg}^{2+}$ bind to the mutant well and provide good activation, $\mathrm{Sr}^{2+}$ is intermediate in these properties, while $\mathrm{Ba}^{2+}$ binds to the mutant but does not activate it (Table 2). In addition, the $K_{\mathrm{d}}^{\text {app }}$ (and $K_{\mathrm{i}}^{\text {app})}$ values correlate approximately with the ionic radii: $\mathrm{Mg}^{2+}(0.66 \AA)<\mathrm{Ca}^{2+}$ $(0.99 \AA)<\mathrm{Sr}^{2+}(1.12 \AA)<\mathrm{Ba}^{2+}(1.35 \AA)(34)$ with the $\mathrm{Ca}^{2+}$ ion best fitting the binding site. Although the exact cause for the different catalytic effects of $\mathrm{Mg}^{2+}$ and $\mathrm{Ca}^{2+}$ is not clear without structural information, we suspect that upon arginine to aspartate mutation at position 69 , the ligand donor atoms may not readily form a well-defined octahedral geometry that favors $\mathrm{Mg}^{2+}$. On the other hand, this coordination sphere may favor $\mathrm{Ca}^{2+}$, which forms looser complexes of higher and variable coordination numbers, without directionality, and with variable bond lengths (34).

In contrast to the alkaline earth metal ions, $\mathrm{Co}^{2+}, \mathrm{Mn}^{2+}$, and $\mathrm{Cd}^{2+}$ provide different activity-versus-metal ion concentration profiles (Figure 3B). These transition metal ions increase the activity of the R69D mutant at low concentrations, reaching maxima at the concentrations of 25,50 , and $100 \mu \mathrm{M}$ for $\mathrm{Cd}^{2+}, \mathrm{Mn}^{2+}$, and $\mathrm{Co}^{2+}$, respectively. The maximal activation is less than 7-fold for $\mathrm{Cd}^{2+}$, ca. 14-fold for $\mathrm{Mn}^{2+}$, and 18-fold for $\mathrm{Co}^{2+}$. Further increases in metal concentration inhibit the enzyme activity, although it stays above the background level even at $1 \mathrm{mM}$ concentration for both $\mathrm{Mn}^{2+}$ and $\mathrm{Co}^{2+}$. The inhibitory effect of $\mathrm{Cd}^{2+}$ is stronger, and $\mathrm{Zn}^{2+}$ totally abolishes the activity of the enzyme at $<1 \mathrm{mM}$ concentration.

In addition, the effects of alkaline (monovalent) metal ions on the activity of R69D were tested. $\mathrm{Na}^{+}, \mathrm{K}^{+}$, and $\mathrm{Cs}^{+}$ showed no activation, whereas $\mathrm{Li}^{+}$gave a 5 -fold activation at saturating concentrations. None of these monovalent metal ions inhibits the $\mathrm{Ca}^{2+}$-induced activity of R69D. Therefore, the sodium ions in the assay system, which were introduced through EDTA and HEPES buffer, should not contribute to the activation and inhibition effects from divalent metal ions described above. Since the activation from $\mathrm{Li}^{+}$is mild and is not likely due to any specific binding to the active site of R69D, the exact cause for this activation was not further pursued.

As a control, the activity of WT bPI-PLC was also examined in the presence of various metal ions. $\mathrm{Li}^{+}, \mathrm{Na}^{+}$, $\mathrm{K}^{+}, \mathrm{Cs}^{+}, \mathrm{Mg}^{2+}, \mathrm{Ca}^{2+}, \mathrm{Sr}^{2+}, \mathrm{Ba}^{2+}$, and $\mathrm{Mn}^{2+}$ all showed slight activation effects $(\leq 30 \%)$, whereas $\mathrm{Co}^{2+}, \mathrm{Cd}^{2+}, \mathrm{Ni}^{2+}$, and $\mathrm{Zn}^{2+}$ brought about severe inhibition. The mechanism of the slight activation effect of some metal ions is not likely due to any specific binding to the WT enzyme as indicated by the ${ }^{15} \mathrm{~N}-{ }^{1} \mathrm{H}$ HSQC experiments (described in a later section). The mechanism of the inhibitory effect of some other divalent ions, which has been observed previously (35), could be due to the nonspecific binding of the ions at or near the active site. Therefore, the observed activation of R69D bPI-PLC by various metal ions is a specific property of this mutant, most likely resulting from the metal ion binding at the active site.

Structural Evidence for the Catalytic Metal Site in R69D. Heteronuclear NMR spectroscopy was used to examine the possible changes introduced by R69D mutation. We found that the mutation alters signal positions and intensities in both the backbone amide region and arginine side chain $\left({ }^{6} \mathrm{NH}\right)$ region of the ${ }^{15} \mathrm{~N}-{ }^{1} \mathrm{H}$ HSQC spectra. Although the changes in the backbone amide region cannot be rationalized without a complete NMR assignment, the changes in the 

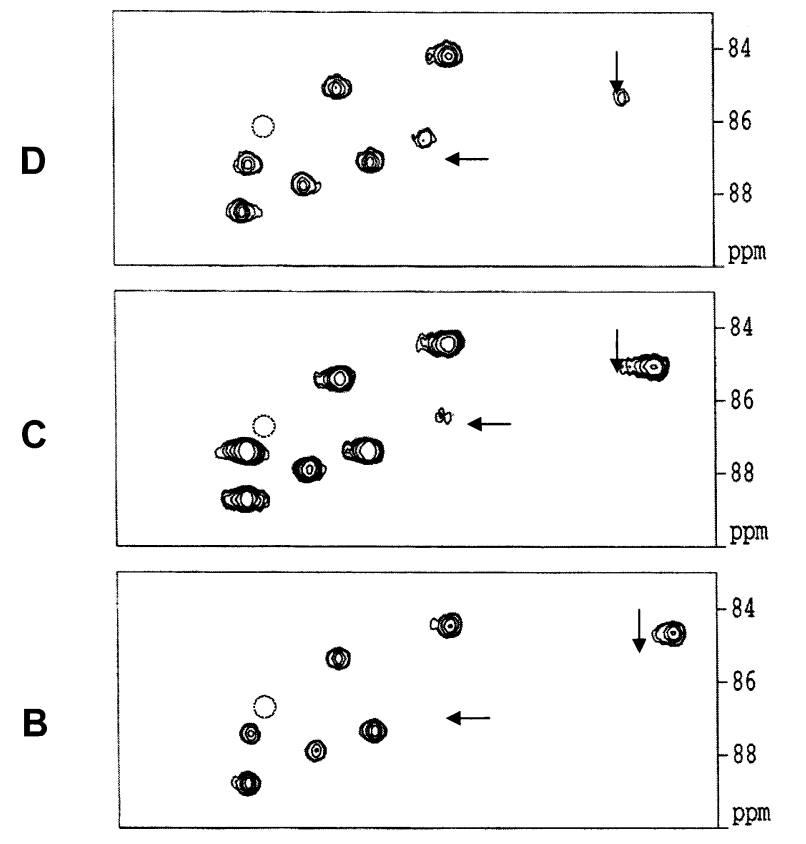

A

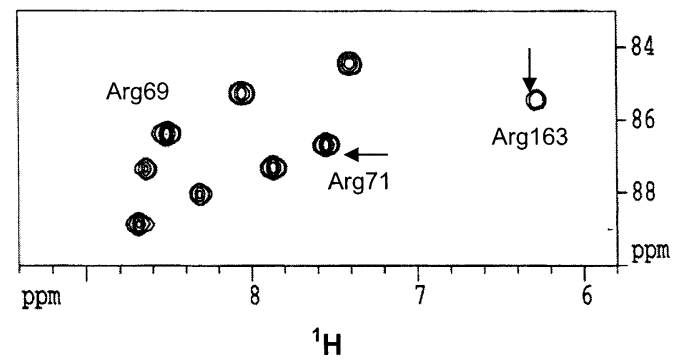

FIGURE 4: Arginine side chain $\left({ }^{\epsilon} \mathrm{NH}\right)$ region of ${ }^{15} \mathrm{~N}-{ }^{1} \mathrm{H}$ HSQC spectra of uniformly ${ }^{15} \mathrm{~N}$-labeled bPI-PLC: (A) WT; (B) R69D; (C) $\mathrm{R} 69 \mathrm{D}$ in the presence of $1 \mathrm{mM} \mathrm{CaCl}_{2}$; and (D) $\mathrm{R} 69 \mathrm{D}$ in the presence of $5 \mathrm{mM} \mathrm{CaCl}_{2}$. Horizontal arrows indicate the position of the signal from Arg71, vertical arrows indicate the position of the signal from Arg163, and the open circle with dashed line represents the missing signal from Arg69 in R69D.

arginine region are informative for the following reasons: (i) The WT enzyme $(35 \mathrm{kDa})$ possesses nine arginine residues, each giving a separate signal in the arginine region of the ${ }^{15} \mathrm{~N}-{ }^{-1} \mathrm{H}$ HSQC spectrum. (ii) Three arginine signals (Arg69, Arg71, and Arg163) have been assigned based on the comparison between the spectrum of WT and those of the corresponding alanine mutants (unpublished results). (iii) Arg71 and Arg163 are adjacent to the active site, while other arginine residues are distant from the active site.

The comparison between the ${ }^{15} \mathrm{~N}-{ }^{1} \mathrm{H}$ HSQC spectra of WT and R69D in their arginine side chains $\left({ }^{\epsilon} \mathrm{NH}\right)$ region (Figure 4A,B) shows that the signals of Arg69 and Arg71 disappeared, while the signal of Arg163 is shifted slightly upfield in the R69D mutant. In the absence of global conformational differences between WT and R69D, as indicated by 2-D NOESY spectra (data not shown), these signal changes/disappearances should be expected for those residues that are either mutated or adjacent to the mutation site. Upon $\mathrm{Ca}^{2+}$ titration of the R69D mutant (Figure 4C,D), the signal from Arg71 gradually reappears at the same position as WT, while the signal of Arg163 shifts back to its original position. As a control, the WT enzyme was also titrated with $\mathrm{Ca}^{2+}$ while the ${ }^{15} \mathrm{~N}-{ }^{1} \mathrm{H}$ HSQC spectra were monitored. No noticeable change was observed in either the backbone amide region or arginine region of the ${ }^{15} \mathrm{~N}-{ }^{1} \mathrm{H}$
HSQC spectrum (data not shown). These results suggest that the R69D mutation triggers local conformational changes and/or perturbed dynamic properties at or near the active site. In addition, binding of $\mathrm{Ca}^{2+}$ to R69D restores the environment of the catalytic site analogous to that attained by the WT enzyme. Taken together, these results strongly support the hypothesis that $\mathrm{Ca}^{2+}$ binds to the active site of the R69D mutant, occupies the position of the Arg69 side chain in the WT enzyme, and thereby activates R69D.

Stereochemical Evidence for the Catalytic Metal Site. As has been shown earlier $(22,24,28)$, Arg69 is the key residue responsible for the WT's unusually large thio effect toward $S_{\mathrm{P}}$-DPPsI $\left(k_{O} / k_{S \mathrm{P}}=3.1 \times 10^{5}\right)$ and very high stereoselectivity $\left(k_{R \mathrm{p}} / k_{S \mathrm{p}}=7600\right)$. Results from these studies not only provided evidence for a direct interaction between the guanidinium group of Arg69 and pro-S oxygen of the substrate but also suggested that the bidentate interactions of Arg69 during the transition state (hydrogen bonds to both $2-\mathrm{OH}$ and pro-S oxygen of the substrate) could be responsible for these observations. In the study reported previously (16), a systematic analysis of the origin of the unusually high nonbridging thio effect was conducted through a site-directed chemical modification method-the arginine residue at position 69 was replace by a cysteine residue and then chemically attached to acetamidine (AA), thioacetamidine (TAA), propylamine (PA), and ethylamine (EA). The mutant enzymes featuring bidentate side chains (R69C-AA and R69C-TAA) at position 69 display significantly higher activity, higher nonbridging thio effect, and greater stereoselectivity than do those with monodentate side chains (R69C-PA and R69CEA) (Table 3).

The magnitude of the $S_{\mathrm{P}}$-thio effect was expected to be decreased in the R69D mutant resulting in a relaxed $R_{\mathrm{P}} / S_{\mathrm{P}}$ stereoselectivity, as has been demonstrated by other Arg69 mutants (e.g., R69K, R69A, R69C-PA, and R69C-EA) (28). If $\mathrm{Ca}^{2+}$ indeed substitutes functionally for the side chain of Arg69, as has been demonstrated in the conservative R69 mutants (R69C-AA and R69C-TAA) (28), the presence of $\mathrm{Ca}^{2+}$ should restore some of the stereoselectivity lost in R69D. To test this hypothesis, we determined the stereoselectivity of R69D in the presence and absence of $\mathrm{Ca}^{2+}$ by ${ }^{31} \mathrm{P}$ NMR. The data, along with those from previous studies (28), are also summarized in Table 3.

The results in Table 3 raise several important points. (i) In the absence of $\mathrm{Ca}^{2+}$, R69D demonstrated a $S_{\mathrm{P}}$-thio effect $\left(k_{O} / k_{S \mathrm{p}}\right)$ of $7.8 \times 10^{2}$, which is ca. 3 orders of magnitude lower than that of WT $\left(k_{O} / k_{S \mathrm{p}}=3.1 \times 10^{5}\right)$. Upon $\mathrm{Ca}^{2+}$ activation, the $S_{\mathrm{P}}$-thio effect $\left(k_{o} / k_{S \mathrm{p}}=4.4 \times 10^{5}\right)$ was restored to the WT level. These results suggest that the bound $\mathrm{Ca}^{2+}$ is likely to mimic the bidentate nature of Arg69 and is responsible for the very large $S_{\mathrm{P}}$-thio effect. (ii) In the absence of $\mathrm{Ca}^{2+}$, the $R_{\mathrm{P}}$-thio effect $\left(k_{O} / k_{R \mathrm{p}}=0.6\right)$ of $\mathrm{R} 69 \mathrm{D}$ is close to unity; this $R_{\mathrm{P}}$-thio effect increases to 9.4 upon $\mathrm{Ca}^{2+}$ addition. The latter value is modestly lower than that of WT $\left(k_{o} / k_{R \mathrm{p}}=42\right)$. Together with the structural data obtained in the previous section, we postulate that the small $R_{\mathrm{P}}$-thio effect demonstrated by R69D originates from increased flexibility in the active site, which allows the enzyme to accommodate a sulfur atom at the pro- $R$ position. Binding of $\mathrm{Ca}^{2+}$ to R69D likely restores the network of active site interactions, causing this mutant to more closely resemble WT enzyme structurally. This would explain why the $R_{\mathrm{P}^{-}}$ 
Table 3: Specific Activity, Thio Effects, and Stereoselectivities of WT and R69D bPI-PLC

\begin{tabular}{|c|c|c|c|c|c|c|c|}
\hline \multirow[b]{2}{*}{ Enzymes } & \multirow[b]{2}{*}{ Functional Group } & \multirow{2}{*}{$\frac{\mathrm{PI}^{a}}{\mathrm{k}_{\mathrm{O}}{ }^{c}}$} & \multicolumn{2}{|c|}{$\mathrm{R}_{\mathrm{P}}-\mathrm{DPPsI}{ }^{b}$} & \multicolumn{2}{|c|}{$\mathrm{S}_{\mathrm{P}-\mathrm{DPPSI}}{ }^{b}$} & \multirow[b]{2}{*}{$\mathrm{k}_{\mathrm{Rp}} / \mathrm{k}_{\mathrm{Sp}}$} \\
\hline & & & $\mathrm{k}_{\mathrm{Rp}}{ }^{c}$ & $\mathrm{k}_{\mathrm{O}} / \mathrm{k}_{\mathrm{Rp}}$ & $\mathrm{k}_{\mathrm{Sp}}{ }^{c}$ & $\mathrm{k}_{\mathrm{O}} / \mathrm{k}_{\mathrm{Sp}}$ & \\
\hline $\mathrm{WT}^{d}$ & & 2200 & 53 & 42 & 0.007 & $3.1 \times 10^{5}$ & 7,600 \\
\hline R69D & & 0.29 & 0.48 & 0.6 & 0.00037 & $7.8 \times 10^{2}$ & 1,300 \\
\hline $\mathrm{R} 69 \mathrm{D}-\mathrm{Ca}^{2+}$ & & 12 & 1.3 & 9.4 & 0.000027 & $4.4 \times 10^{5}$ & 47,000 \\
\hline $\mathrm{R} 69 \mathrm{C}-\mathrm{AA}^{d}$ & & 160 & 4.0 & 40 & 0.001 & $1.6 \times 10^{5}$ & 4,000 \\
\hline $\mathrm{R}^{69} \mathrm{C}-\mathrm{TAA}^{d}$ & & 50 & 1.3 & 38 & 0.0004 & $1.2 \times 10^{5}$ & 3,000 \\
\hline $\mathrm{R} 69 \mathrm{C}-\mathrm{PA}^{d}$ & & 1.5 & 0.043 & 35 & 0.0038 & $3.9 \times 10^{2}$ & 11 \\
\hline $\mathrm{R} 69 \mathrm{C}-\mathrm{EA}^{d}$ & & 0.50 & 0.014 & 36 & 0.0046 & $1.1 \times 10^{2}$ & 3.0 \\
\hline $\mathrm{R} 69 \mathrm{~K}^{d}$ & & 0.1 & 0.0029 & 34 & 0.003 & $2.7 \times 10$ & 1 \\
\hline
\end{tabular}

\footnotetext{
${ }^{a}$ Measured by radioactive assay. ${ }^{b}$ Measured by ${ }^{31} \mathrm{P}$ NMR. ${ }^{c}$ In $\mu \mathrm{mol} \mathrm{min}^{-1} \mathrm{mg}^{-1} \cdot{ }^{d}$ R69C-AA, R69C-TAA, R69C-PA, and R69C-EA are chemically modified R69C mutants (28). AA, TAA, PA, and EA stand for the covalently linked functional groups acetamidine, thioacetamidine, propylamine, and ethylamine, respectively.
}

thio effect for R69D increases upon $\mathrm{Ca}^{2+}$ activation. (iii) The observed stereoselectivity $\left(k_{R \mathrm{p}} / k_{S \mathrm{p}}\right)$ can be dissected into the ratio of the thio effects for both $R_{\mathrm{P}^{-}}$and $S_{\mathrm{P}}$-isomers, $\left(k_{\mathrm{O}} /\right.$ $\left.k_{S_{\mathrm{p}}}\right) /\left(k_{\mathrm{O}} / k_{R \mathrm{p}}\right)$. In the presence of $\mathrm{Ca}^{2+}$, the R69D mutant $\left(\mathrm{R} 69 \mathrm{D}-\mathrm{Ca}^{2+}\right)$ shows a similar $S_{\mathrm{P}}$-thio effect but a decreased $R_{\mathrm{P}}$-thio effect, as compared to the WT enzyme. Consequently, R69D- $\mathrm{Ca}^{2+}$ displays higher stereoselectivity $\left(k_{R \mathrm{p}} / k_{S \mathrm{p}}=\right.$ $47000)$ than WT $\left(k_{R \mathrm{p}} / k_{S \mathrm{p}}=7600\right)$. However, this increased stereoselectivity does not originate from a more stringent discrimination of $\mathrm{Ca}^{2+}$ against the sulfur atom (in forming the coordination sphere) as compared to that of the arginine side chain (in forming a hydrogen bonding interaction). Rather, this increase in stereoselectivity is derived from the greater flexibility of R69D- $\mathrm{Ca}^{2+}$ in accommodating a sulfur atom at the pro- $R$ position of the substrate thus resulting in a relatively small $R_{\mathrm{P}}$-thio effect.

Comparison with Streptomyces antibioticus PI-PLC1. Recently, a bacterial PI-PLC from S. antibioticus (saPLC1) has been shown to be $\mathrm{Ca}^{2+}$-dependent (36). We found that saPLC1 displays an extraordinarily high $S_{\mathrm{P}}$-thio effect $\left(k_{O} /\right.$ $\left.k_{S \mathrm{p}}=1.6 \times 10^{8}\right)$ and very high stereoselectivity $\left(k_{R \mathrm{p}} / k_{S \mathrm{p}}=\right.$ $\left.6.2 \times 10^{6}\right)$ in the presence of $\mathrm{Ca}^{2+}(37)$. Both values are 2 orders of magnitude higher than those for WT bPI-PLC as well as $\mathrm{R} 69 \mathrm{D}-\mathrm{Ca}^{2+}$, which are already among the highest of all enzymes. The detailed mechanistic differences between saPLC1 and R69D $-\mathrm{Ca}^{2+}$ remain to be established. However, examination of thio effects indicates that the higher stereoselectivity of saPLC1 is derived mainly from a higher $S_{\mathrm{P}^{-}}$ thio effect. Further structural and mechanistic comparison between saPLC1 and R69D- $\mathrm{Ca}^{2+}$ will likely enhance our understanding of the catalytic roles of $\mathrm{Ca}^{2+}$ in various enzymes.

Further Characterization of the Metal Ion Binding Site Using Multiple Mutants. Since the results in the two preceding sections suggest that the $\mathrm{Ca}^{2+}$ ion should bind to R69D bPI-PLC at the position occupied by the guanidinium group in the WT enzyme, its coordination sphere is expected to include the side chains of Asp33, Asp67, and Glu117 [i.e., the same residues that are hydrogen-bonded to the Arg69 side chain in the WT enzyme $(17,26,38)]$ as well as the newly introduced Asp69 (Figure 2C). To verify the participation of these amino acids in the metal coordination, all three carboxylic acid residues potentially participating in metal ion coordination were mutated (one at a time) to create the following double mutants: D33N/R69D, D33E/R69D, D67N/ R69D, D67E/R69D, R69D/E117Q, and a triple mutant D33N/D67E/R69D.

As shown in Table 1, in the absence of metal ions the activities of the three double mutants D67N/R69D, D67E/ R69D, and R69D/E117Q are of the same magnitude as of R69D. However, none of the three can be activated by $\mathrm{Ca}^{2+}$. These results suggest that Asp67 and Glu117 are involved in the binding of $\mathrm{Ca}^{2+}$.

Asp33, which forms a hydrogen bond with Arg69 in the WT enzyme, should also be involved in $\mathrm{Ca}^{2+}$ binding in R69D on the basis of the following results. The activities of all three mutants involving this residue, D33N/R69D, D33E/ R69D, and D33N/D67E/R69D, are all lower than that of the 


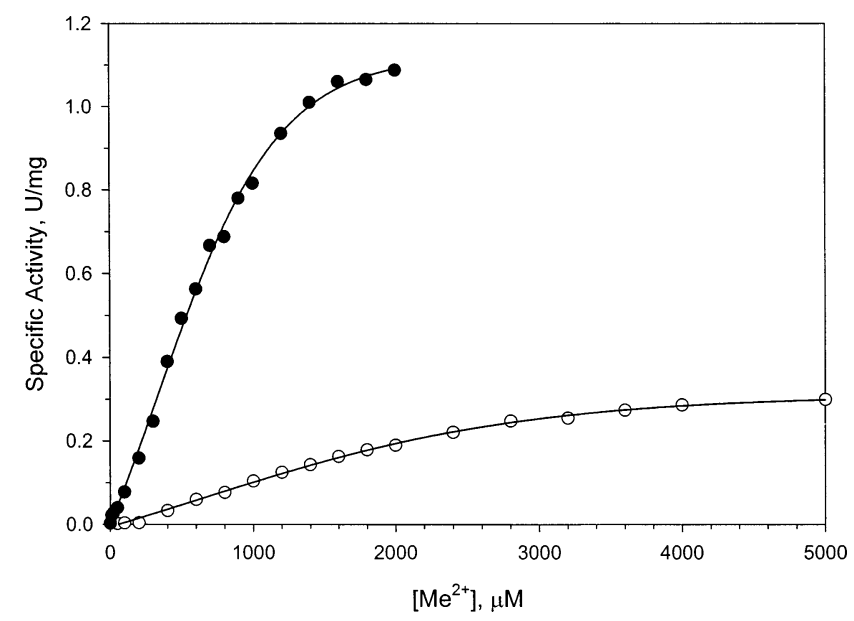

FIGURE 5: Activation of D33N/R69D bPI-PLC by magnesium ( and calcium $(\mathrm{O})$. All reactions included $12-26 \mu \mathrm{g}$ of enzyme in $40 \mathrm{mM}$ HEPEPS, $1 \mathrm{mM}$ EDTA, $2 \mathrm{mM}$ PI, $8 \mathrm{mM}$ DHPC, and 0-1 $\mathrm{mM}$ free metal ions, $\mathrm{pH} 7.0$, for $10 \mathrm{~min}$ at $37{ }^{\circ} \mathrm{C}$. Solid lines represent nonlinear fit of each data set to the Hill equation, $V=$ $V_{\max }\left[\mathrm{M}^{2+}\right]^{n} /\left(\left(K_{\mathrm{d}}^{\mathrm{app}}\right)^{n}+\left[\mathrm{M}^{2+}\right]^{n}\right)$, and the parameters are summarized as follows: $\mathrm{Mg}^{2+}, V_{\max }=1.35 \pm 0.05 \mathrm{U} / \mathrm{mg}, K_{\mathrm{d}}^{\text {app }}=0.73 \pm 0.04$ $\mathrm{mM}$, and $n=1.5 ; \mathrm{Ca}^{2+}, V_{\max }=0.37 \pm 0.01 \mathrm{U} / \mathrm{mg}, K_{\mathrm{d}}{ }^{\mathrm{app}}=1.9 \pm$ $0.1 \mathrm{mM}$, and $n=1.6$

R69D single mutant by 2 orders of magnitude. Noticeably, the D33N/R69D mutant is activated by $1 \mathrm{mM} \mathrm{Ca}^{2+}$ ca. $50-$ fold. This prompted us to further examine the behavior of this mutant. As shown in Figure 5, its activation by $\mathrm{Mg}^{2+}$ and $\mathrm{Ca}^{2+}$ has a somewhat sigmoidal form, and the maximal activations are 560- and 150-fold, respectively. Furthermore, the apparent dissociation constant of $\mathrm{Mg}^{2+}$ is almost 3-fold lower than that of $\mathrm{Ca}^{2+}$ as given in the legend of Figure 5 . This modest preference of $\mathrm{Mg}^{2+}$ over $\mathrm{Ca}^{2+}$ is most likely due to the fact that $\mathrm{Ca}^{2+}$ favors ligands without nitrogen donors, while $\mathrm{Mg}^{2+}$ is more flexible in this regard (34). This discrimination comes at a price of lower maximal activity (1.35 vs $10.2 \mathrm{U} / \mathrm{mg}$ with $\mathrm{Mg}^{2+}$ and 0.37 vs $11.9 \mathrm{U} / \mathrm{mg}$ with $\left.\mathrm{Ca}^{2+}\right)$ and lower affinity toward metal ions (0.73 vs 0.18 $\mathrm{mM}$ for $\mathrm{Mg}^{2+}$ and 1.9 vs $0.16 \mathrm{mM}$ for $\mathrm{Ca}^{2+}$ ) for this mutant in comparison to R69D.

The analyses presented above provide experimental support for the hypothesis that metal coordination at the active site involves the side chains from Asp33, Asp67, Asp69, and Glu117. On the basis of the results in the preceding section, the pro-S oxygen of the phosphate group and possibly the 2-OH group from the substrate should further complement the coordination sphere.

\section{CONCLUSION}

The results described here represent the first example of successful engineering of a catalytically functional metal binding site of an enzyme based on mimicry of a positively charged amino acid side chain (arginine) by a divalent metalbinding carboxylate residue. Knowledge of the precise positioning of active site residues and the reaction mechanisms involved were the key factors facilitating our design. The engineered enzyme is characterized by strong metal ion binding and high $R_{\mathrm{P}} / S_{\mathrm{P}}$ stereoselectivity, reminiscent of other $\mathrm{Ca}^{2+}$-dependent PI-PLCs. On the basis of the results obtained, it is concluded that the functional switch of Arg69 into Asp $-\mathrm{Ca}^{2+}$ has been achieved. Further investigation of this engineered metal-dependent bPI-PLC in the context of other naturally occurring calcium-dependent PI-PLCs could provide insight into how enzymes have evolved from metalindependence to metal-dependence, as well as how the metal binding site is fine-tuned for optimal specificity and catalytic function through the evolutionary process.

\section{ACKNOWLEDGMENT}

We thank Dr. Chunhua Yuan for technical assistance in performing ${ }^{15} \mathrm{~N}-{ }^{1} \mathrm{H}$ HSQC experiments and Dr. George Barber and Brandon Lamarch for helpful discussions.

\section{REFERENCES}

1. Regan, L. (1993) Annu. Rev. Biophys. Biomol. Struct. 22, 25787.

2. Regan, L. (1995) Trends Biochem. Sci. 20, 280-5.

3. Lu, Y., and Valentine, J. S. (1997) Curr. Opin. Struct. Biol. 7, 495-500.

4. He, M. M., Voss, J., Hubbell, W. L., and Kaback, H. R. (1995) Biochemistry 34, 15661-6.

5. He, M. M., Voss, J., Hubbell, W. L., and Kaback, H. R. (1995) Biochemistry 34, 15667-70.

6. Higaki, J. N., Haymore, B. L., Chen, S., Fletterick, R. J., and Craik, C. S. (1990) Biochemistry 29, 8582-6.

7. McGrath, M. E., Haymore, B. L., Summers, N. L., Craik, C. S., and Fletterick, R. J. (1993) Biochemistry 32, 1914-9.

8. Wilcox, S. K., Putnam, C. D., Sastry, M., Blankenship, J., Chazin, W. J., McRee, D. E., and Goodin, D. B. (1998) Biochemistry 37. 16853-62.

9. Casareno, R., Li, D., and Cowan, J. A. (1995) J. Am. Chem. Soc. $117,11011-2$.

10. Berridge, M. J., and Irvine, R. F. (1984) Nature 312, 315-21.

11. Berridge, M. J. (1995) Ann. N.Y. Acad. Sci. 766, 31-43.

12. Bruzik, K. S., and Tsai, M.-D. (1994) Bioorg. Med. Chem. 2, 4972.

13. Lee, S. B., and Rhee, S. G. (1995) Curr. Opin. Cell Biol. 7, 1839.

14. Camilli, A., Goldfine, H., and Portnoy, D. A. (1991) J. Exp. Med. 173, 751-4.

15. Songer, J. G. (1997) Trends Microbiol. 5, 156-61.

16. Bruzik, K. S., Morocho, A. M., Jhon, D. Y., Rhee, S. G., and Tsai, M.-D. (1992) Biochemistry 31, 5183-93.

17. Heinz, D. W., Ryan, M., Bullock, T. L., and Griffith, O. H. (1995) EMBO J. 14, 3855-63.

18. Essen, L. O., Perisic, O., Cheung, R., Katan, M., and Williams, R. L. (1996) Nature 380, 595-602.

19. Heinz, D. W., Essen, L. O., and Williams, R. L. (1998) J. Mol. Biol. 275, 635-50.

20. Gassler, C. S., Ryan, M., Liu, T., Griffith, O. H., and Heinz, D. W. (1997) Biochemistry 36, 12802-13.

21. Hondal, R. J., Bruzik, K. S., Zhao, Z., and Tsai, M.-D. (1997) J. Am. Chem. Soc. 119, 5477-8.

22. Hondal, R. J., Riddle, S. R., Kravchuk, A. V., Zhao, Z., Liao, H., Bruzik, K. S., and Tsai, M.-D. (1997) Biochemistry 36, 663342.

23. Hondal, R. J., Zhao, Z., Riddle, S. R., Kravchuk, A. V., Liao, H., Bruzik, K. S., and Tsai, M.-D. (1997) J. Am. Chem. Soc. 119, 9933-4.

24. Hondal, R. J., Zhao, Z., Kravchuk, A. V., Liao, H., Riddle, S. R., Yue, X., Bruzik, K. S., and Tsai, M.-D. (1998) Biochemistry 37, $4568-80$.

25. Kubiak, R. J., Hondal, R. J., Yue, X., Tsai, M.-D., and Bruzik, K. S. (1999) J. Am. Chem. Soc. 121, 488-9.

26. Heinz, D. W., Ryan, M., Smith, M. P., Weaver, L. H., Keana, J. F., and Griffith, O. H. (1996) Biochemistry 35, 9496-504.

27. Lin, G. L., Bennett, C. F., and Tsai, M.-D. (1990) Biochemistry 29, 2747-57.

28. Kravchuk, A. V., Zhao, L., Kubiak, R. J., Bruzik, K. S., and Tsai, M.-D. (2001) Biochemistry 40, 5433-9.

29. Kubiak, R. J., Yue, X., Hondal, R. J., Mihai, C., Tsai, M.-D., and Bruzik, K. S. (2001) Biochemistry 40, 5422-32.

30. Ellis, M. V., James, S. R., Perisic, O., Downes, C. P., Williams, R. L., and Katan, M. (1998) J. Biol. Chem. 273, 11650-9. 
31. McPhalen, C. A., Strynadka, N. C., and James, M. N. (1991) Adv. Protein Chem. 42, 77-144.

32. Rebecchi, M. J., and Rosen, O. M. (1987) J. Biol. Chem. 262, 12526-32.

33. Grobler, J. A., and Hurley, J. H. (1998) Biochemistry 37, 50208.

34. Martin, R. B. (1984) Metal Ions Biol. Syst. 17, 1-43.

35. Taguchi, R., Asahi, Y., and Ikezawa, H. (1980) Biochim. Biophys. Acta 619, 48-57.
36. Iwasaki, Y., Tsubouchi, Y., Ichihashi, A., Nakano, H., Kobayashi, T., Ikezawa, H., and Yamane, T. (1998) Biochim. Biophys. Acta $1391,52-66$.

37. Zhao, L., Liu, Y., Bruzik, K. S., and Tsai, M.-D. (2003) J. Am. Chem. Soc. 125, 22-23.

38. McConnell, T. S., Herschlag, D., and Cech, T. R. (1997) Biochemistry 36, 8293-303.

BI0271953 